\title{
Impact of the Ultrasonic scalpel on the amount of drained lymph after axillary or inguinal lymphadenectomy
}

\author{
Olivier Gié*, Marie-Laure Matthey-Gié, Pedro-Manuel Marques-Vidal, Nicolas Demartines and Maurice Matter
}

\begin{abstract}
Background: Seroma formation and lymphoedema are frequently encountered complications after radical lymph node dissection (RLND). Attempts to reduce the lymphatic morbidity include the use of Ultrasonic Scalpel. The aim of the present analysis was to assess the impact of the ultrasonic scalpel on the amount of drained lymph after lymph node dissection.
\end{abstract}

Methods: Patients listed for a RLND or completion lymph node dissection (CLND) were enrolled in a prospective randomized trial to compare the impact of two surgical dissection techniques (USS versus control) on the amount of drained lymph. The lymph drained in $24 \mathrm{~h}$ was collected. Our primary endpoint was to compare the daily amount of drained lymph between the two groups. Secondary endpoints were the comparison of drained lymph with the BMI of the patients, the gender and the surgical site (axilla, groin).

Results: Eighty patients were randomly assigned to the USS group or the Control (C) group. No difference was measured in the total amount of lymph drained (USS: $2908 \pm 2453 \mathrm{ml} v$ s. C: $3898 \pm 5791 \mathrm{ml}$; $p$-value =0.382). The result was also similar after adjusting for gender, age, and BMI. A significant higher amount of lymph was measured after inguinal dissection with USS compared to axillary $(p<0.001)$.

Conclusion: The study suggests that the use of Harmonic scalpel did not influence the amount of lymph drained after RLND and not support the theory that USS induces oversealing of lymphatics.

Trial registration: Clinical Trial NCT02476357. Registered 20 of February 2015.

Keywords: Lymphatics, Radical lymph node dissection, Surgical morbidity, Harmonic scalpel

\section{Background}

Radical lymph node dissection (RLND) plays an essential role in staging and control of locoregional disease in both skin cancers and soft tissue tumours. The indication for RLND in the axilla or in the groin is the discovery of a clinical evident lymph node macrometastasis or a micrometastasis after lymph node biopsy. Important postoperative complication such as lymphocoele, lymphorrhoea and lymphoedema may occur in up to $50 \%$ of cases [1-3]. Lymphoedema has been shown to increase postoperative discomfort and can result in limb disability [4] or lead to septic complications as cellulitis and lymphangitis [5].

\footnotetext{
* Correspondence: olivier.gie@chuv.ch; http://www.chirurgieviscerale.ch Department of Visceral Surgery, University Hospital of Lausanne, Rue du Bugnon 46, Lausanne, CHUV 1011, Switzerland
}

Such complications increase the costs of surgery and have a negative effect on the quality of life [6]. Attempts to reduce lymphatic morbidity (use of fibrin glue, vacuum dressing or modifications of surgical techniques) have been discussed in the literature without showing significant benefits $[7,8]$.

The use of the ultrasonic scalpel (USS) has been suggested to have a positive impact on morbidity, in trial data from breast surgery patients $[3,9]$. However, subsequent trials have cast doubt on this effect $[10,11]$. A recent randomized trial conducted on patients treated for melanoma, skin cancer and sarcoma showed a higher rate of lymphoedema in patients operated with USS [12]. The author's hypothesis was that the USS ensures a more efficient sealing compared to diathermy, resulting in a higher rate of lymphostasys in the operated limb. In 
the same way a randomized trial focused on gastric cancer supports this hypothesis reporting a postoperative reduction of lymphorrhoea when USS was used [13].

The choice of dissecting device is not the sole determinant of the amount of drained lymph after RLND. When compared with axillary dissection, there is some evidence to suggest that radical inguinal node dissection is associated with an higher rate of drained lymph and consequently a higher rate of lymphoedema and lymphorrhoea. [14] It is logical to believe that a bigger limb may produce a greater amount of lymph compared to a smaller one, i.e., the lower limb compared to the upper limb. In the same way, studies focusing on breast cancer have suggested a direct correlation between body mass index and lymphatic specific morbidity [15]. However, this has not been confirmed in other trials $[16,12]$, and there is much debate regarding the impact of the BMI on lymphatic morbidity. Use of a Redon suction drain to evacuate the amount of lymph lost by unsealed lymph vessels after inguinal and axillary RLND is an effective approach to reduce lymphatic complications $[17,18]$. The aim of this study is to analyze if the use of the ultrasonic scalpel (USS) can influence the amount of drained lymph after radical lymph node dissection when compared with classical dissection conducted with monopolar scalpel and ligature (control).

\section{Methods}

This was a single-centre randomised controlled trial conducted in a tertiary academic institution between March 2009 and November 2013. Patients listed for an inguinal or axillary RLND or completion lymph node dissection (CLND) after positive sentinel lymph node biopsy (SLNB) for melanoma, skin cancer or sarcoma were invited to participate in a randomised controlled trial. Consenting patients were randomised into two treatment arms, a USS group and a control group. Details of the study design have been published previously [19]. The study protocol was accepted by the local ethics committee and registered under ClinicalTrials.gov (trial no. NCT02476357). Patients older than 18 years and listed for elective lymphadenectomy with capacity to provide informed consent were eligible for inclusion. Patients with insufficient follow up data or undergoing both iliac and inguinal RLND were excluded from the analysis. Patient presenting other causes of lymphoedema were also excluded. In the USS group, the dissection was conducted using an Ultrasonic scalpel (Harmonic Focus ${ }^{\circ}$, Ethicon Endo-Surgery (Europe) $\mathrm{GmbH}$ ). In the control group the operation was performed using an electrocautery and ligature.

\section{Follow-up}

Post-operatively, the amount of the drained lymph in $24 \mathrm{~h}$ was daily measured by dedicated staff during the
Table 1 Characteristics of the patients according to type of scalpel

\begin{tabular}{llll}
\hline & USS $(n=39)$ & Control $(n=40)$ & $p$-value \\
\hline Women (\%) & $16(41.0)$ & $16(40.0)$ & 0.926 \\
Age (years) & $59.3 \pm 15.2$ & $61.9 \pm 13.1$ & 0.406 \\
BMI $\left(\mathrm{kg} / \mathrm{m}^{2}\right)$ & $25.6 \pm 4.5$ & $27.0 \pm 5.0$ & 0.184 \\
BMl categories (\%) & & & \\
$\quad-25.0[$ & $18(46.2)$ & $12(30.0)$ & 0.315 \\
$\quad$ 25-30[ & $14(35.9)$ & $20(50.0)$ & \\
$\quad$ 30+ & $7(18.0)$ & $8(20.0)$ & \\
Sentinel node biopsy (\%) & $14(35.9)$ & $14(35.0)$ & 0.934 \\
Procedure (\%) & & & \\
$\quad$ Axillary & $27(69.2)$ & $31(77.5)$ & 0.406 \\
$\quad$ Inguinal & $12(30.8)$ & $9(22.5)$ & \\
\hline
\end{tabular}

$B M I$, body mass index. Results are expressed as number of patients (\%) or as average \pm standard deviation. Between-group comparisons performed using chi-square test for categorical data and Student's $t$-test for quantitative data

hospitalisation. After the discharge the patient recorded on a monitoring sheet the daily amount of lymph present in the drain. The drain was subsequently removed when the lymph flow was less than $50 \mathrm{~mL} / 24 \mathrm{~h}$ for 2 days. Some patients had occasional puncture of residual lymphocele thereafter.

\section{Endpoints and statistical analysis}

Our primary endpoint was to compare the daily amount of drained lymph between the two groups. Secondary endpoints were the comparison of drained lymph with the BMI of the patients, the gender and the surgical site (axilla, groin).

Demographic data collected included age, gender, ASA classification, body max index (BMI), primary tumour and the number of lymph nodes harvested.

Statistical analysis was conducted using Stata version 14.0 for Windows (Stata Corp, College Station, TX, USA). Results were expressed as average \pm standard deviation for continuous data and as number of patients and percentage for categorical data. Between-group comparisons were performed using chi-square for categorical

Table 2 Total volume of lymph drained and duration of draining, according to type of scalpel

\begin{tabular}{llll}
\hline & Harmonic $(n=39)$ & Control $(n=40)$ & $p$-value \\
\hline $\begin{array}{l}\text { Total volume }(\mathrm{ml}) \\
\text { Univariate }\end{array}$ & $2908 \pm 2453$ & $3898 \pm 5791$ & 0.382 \\
$\begin{array}{l}\text { Multivariate-adjusted } \\
\text { Duration of draining (days) }\end{array}$ & $3941 \pm 706$ & 0.293 \\
$\begin{array}{l}\text { Univariate } \\
\text { Multivariate-adjusted }\end{array}$ & $24 \pm 14$ & $28 \pm 15$ & 0.195 \\
$\begin{array}{l}\text { Results are expressed as average } \pm \text { standard deviation or as multivariate-adjusted } \\
\text { average } \pm \text { standard error. Between-group comparisons performed using analysis } \\
\text { of variance adjusting for gender, age (continuous), body mass index (continuous), } \\
\text { procedure and sentinel node biopsy }\end{array}$
\end{tabular}




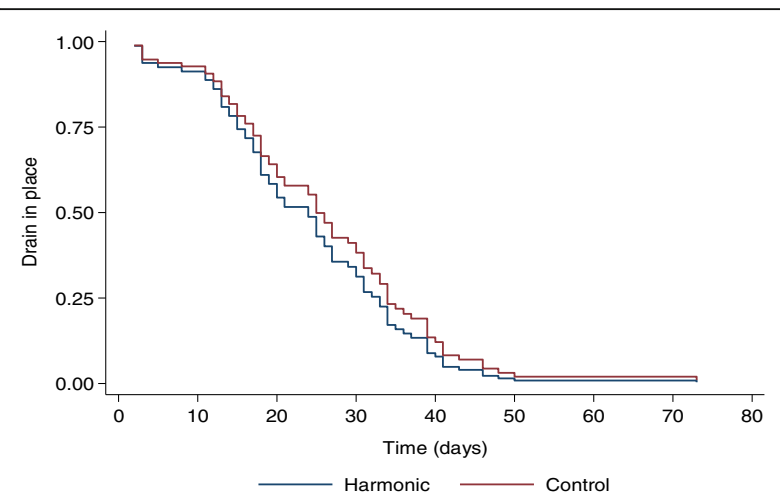

Fig. 1 Time to drain removal according to scalpel. Comparison of control vs. harmonic scalpel using Cox proportional hazards regression adjusting for gender, age (continuous), body mass index $(-25.0$ [, [25-30 [and [30+), procedure and sentinel node biopsy : hazard ratio $0.85,95 \%$ confidence interval $(0.51 ; 1.33), p=0.426$

data and Student's $t$-test for continuous data. Betweengroup multivariate comparisons were performed using analysis of variance adjusting for gender, age (continuous), body mass index (continuous), procedure and sentinel node biopsy; results were expressed as adjusted mean \pm standard error. Multivariable analysis of the amount of drained lymph between the two groups was conducted using a random-intercept, random-slope mixed model taking into account each patient's individual evolution (i.e., a specific intercept and slope for each patient); results were expressed as coefficient and (95\% confidence interval) for each parameter of the fixed model. Time to drain removal was assessed by Cox proportional hazards regression adjusting for gender, age, body mass index, procedure and sentinel node biopsy; results were expressed as hazard ratio and ( $95 \%$ confidence interval). Statistical significance was considered for a two-sided test $p$-value $<0.05$.

\section{Results}

Seventy nine patients were randomly assigned to the USS group or the Control (C) group. Of the 80 eligible patients 1 patient randomized in the USS group was excluded due to insufficient data collection at home. The patient characteristics and the surgical details for included patients are summarized in Table 1. There was no significant difference in baseline characteristics between the two groups.

As reported in Table 2, the duration of drainage according to the type of scalpel was the same in the two groups. No differences were also seen in the average amount and in the multivariate adjusted-average amount of drained lymph between USS and control group. Analysis of variance adjusting for gender, age, BMI, procedure and previous sentinel node biopsy (Fig. 1) confirm these findings. A higher rate of drained lymph was measured after inguinal RLND with USS compared to axillary resection (Table 3).

\section{Discussion}

Lymphoedema and seroma formation are common complications following radical lymph node dissection. They lead to prolonged hospital stay, postoperative discomfort and higher costs. Overall techniques to reduce the problem of lymphatic leak after RLND include regular needle drainage of lymphocele or leaving a suction drain into place. Reduction of the quantity and duration of lymphatic complications will benefit quality of life and costs. In order to reduce the amount of drained lymph and the duration of lymph aspiration, some authors have proposed to avoid level III dissection in the axilla [20], harvesting a lower number of lymph node with a non negligible risk of nodal recurrence [21].

There is a paucity of data regarding the potential benefit of ultrasonic scalpels in reduction of lymphatic complications. A systematic review published by Kuroi et al. in 2006 suggested that Ultrasonic devices generate lower thermal injuries compared to electrocautery and by consequence have a lower rate of lymphatic complications [22]. This hypothesis was based on a case control study conducted on 139 patient undergoing level I and II axillary dissection for breast cancer that showed a significant decrease in drainage output in patients operated with the ultrasonic scalpels [3]. Similar results were found in three other prospective studies [9, 23, 24]. Iovino et al. reported a benefit for ultrasonic devices for axillary RLND in terms of drained lymph and seroma

Table 3 Factors associated with lymph draining

\begin{tabular}{lllll}
\hline & Harmonic & $p$-value & Control & $p$-value \\
\hline Procedure (inguinal vs. axillary) & $2285(799 ; 3770)$ & $<0.001$ & $2272(-1930 ; 6475)$ & 0.290 \\
Sentinel node biopsy (no vs. yes) & $388(-1126 ; 1903)$ & 0.620 & $24(-3470 ; 3517)$ & 0.990 \\
Gender (woman vs. man) & $300(-1165 ; 1764)$ & 0.690 & $2132(-1362 ; 5627)$ & 0.230 \\
Age (per year) & $-9(-56 ; 37)$ & 0.700 & $34(-102 ; 169)$ & 0.630 \\
BMl (per kg/m $\left.\mathrm{m}^{2}\right)$ & $122(-36 ; 279)$ & 0.130 & $-32(-405 ; 342)$ & 0.870 \\
Day & $-123(-144 ;-103)$ & $<0.001$ & $-121(-148 ;-95)$ & $<0.001$ \\
\hline
\end{tabular}

$B M I$, body mass index. Results are expressed as coefficient and 95\% confidence interval (Cl) of the fixed parameters. Statistical analysis by a mixed model using individual origin and day slope as random effect parameters. Test for interaction between type of scalpel and day: $z=0.06, p$-value $=0.953$ 
formation and suggested that ultrasonic scalpels produce an effective sealing of lymphatic vessels, including both those directed to the apex of the axilla and those draining the lymph from the mammary gland, the fascia, and the pectoral muscles to the axillary lymph nodes. These encouraging results were not confirmed by several prospective studies and meta-analysis which compared the amount of drained lymph after mastectomy using ultrasonic devices or electrocautery. Adwani et al., and several subsequent studies report no statistically significant reduction in the drainage volume and rate of seroma development [10, 25-30]. Furthermore, a recent trial [19] has shown a higher rate of lymphoedema after lymphatic dissection conducted with ultrasonic scalpels. The higher rate of lymphoedema in the ultrasonic scalpel group was thought to be explained by an oversealing of the lymphatic vessels. Another hypothesis is that USS could influence lymphangiogenesis. Previous evidence from the literature reported a reduction of $20 \%$ of lymph volume with USS, compared to the control group [3]. Based on those results and adopting a 2 -sided type I error $(\alpha)$ of 0.05 , with a sample size of 80 patients, the calculation yielded a power of $70 \%$ for the present analysis.

\section{Conclusion}

Conducted in a homogeneous group of patients operated systematically by the same surgeon, this study suggests that the use of Harmonic scalpel did not influence the amount of lymph drained after RLND and not support the theory that USS induces oversealing of lymphatics. A subgroup analysis comparing BMI, age, gender, previous lymph node biopsy and type of scalpel failed to show any significantly difference between the ultrasonic scalpel and the electrocautery.

\section{Abbreviations \\ CLND: Completion lymph node dissection; RLND: Radical lymph node dissection; SLNB: Sentinel lymph node biopsy; USS: Ultrasonic scalpel}

\section{Acknowledgements}

Authors would like to thank the staff of the Department of visceral surgery at the University Hospital of Lausanne for help in procuring clinical information in the follow-up of patients.

\section{Funding}

The study was not sponsored by Industry or funding arrangements

\section{Availability of data and materials}

Our database contains sensible data which may provide insight in clinical information about our patients. Therefore, according to organizational restrictions and regulations these data cannot be made publically available. The database will be kept at a research server at Lausanne University Hospital until end of December 2026.

\section{Authors' contributions}

OG, MGML, MM and ND were the main authors of the manuscript. They were involved in the conception, design and coordination of the study as well as in data analysis, interpretation of results and the drafting of the manuscript. MVPM performed the statistical analysis. All authors read and approved the final manuscript.

\section{Competing interests}

The authors declare that they have no competing interests.

\section{Consent to publication}

Not applicable.

Ethics approval and consent to participate

The study protocol was approved by the local ethics committee and an informed consent was obtained from all individual participants.

\section{Publisher's Note}

Springer Nature remains neutral with regard to jurisdictional claims in published maps and institutional affiliations.

Received: 27 October 2016 Accepted: 10 March 2017

Published online: 21 March 2017

\section{References}

1. Di Monta G, Caraco C, Crispo A, Marone U, Mozzillo N. Collagen sealant patch to reduce lymphatic drainage after lymph node dissection. World J Surg Oncol. 2012;10:275

2. van Bemmel AJ, van de Velde CJ, Schmitz RF, Liefers GJ. Prevention of seroma formation after axillary dissection in breast cancer: a systematic review. Eur J Surg Oncol. 2011;37(10):829-35.

3. Lumachi F, Basso SM, Santeufemia DA, Bonamini M, Chiara GB. Ultrasonic dissection system technology in breast cancer: a case-control study in a large cohort of patients requiring axillary dissection. Breast Cancer Res Treat. 2013;142(2):399-404.

4. Petrek JA, Pressman PI, Smith RA. Lymphedema: current issues in research and management. CA Cancer J Clin. 2000:50(5):292-307.

5. Shih YC, Xu Y, Cormier JN, Giordano S, Ridner SH, Buchholz TA. Incidence, treatment costs, and complications of lymphedema after breast cancer among women of working age: a 2-year follow-up study. J Clin Oncol. 2009:27(12):2007-14.

6. Beaulac SM, McNair LA, Scott TE, LaMorte WW, Kavanah MT. Lymphedema and quality of life in survivors of early-stage breast cancer. Arch Surg. 2002;137(11):1253-7.

7. Sajid MS, Hutson KH, Rapisarda IF, Bonomi R. Fibrin glue instillation under skin flaps to prevent seroma-related morbidity following breast and axillary surgery. Cochrane Database Syst Rev. 2013;5:Cd009557.

8. Judson $\mathrm{PL}$, Jonson AL, Paley PJ, Bliss RL, Murray KP, Downs Jr LS. A prospective, randomized study analyzing sartorius transposition following inguinal-femoral lymphadenectomy. Gynecol Oncol. 2004;95(1):226-30.

9. Iovino F, Auriemma PP, Ferraraccio F, Antoniol G, Barbarisi A. Preventing seroma formation after axillary dissection for breast cancer: a randomized clinical trial. Am J Surg. 2012;203(6):708-14.

10. Adwani A, Ebbs SR. Ultracision reduces acute blood loss but not seroma formation after mastectomy and axillary dissection: a pilot study. Int J Clin Pract. 2006;60(5):562-4.

11. Pellegrino A, Fruscio R, Maneo A, Corso S, Battistello M, Chiappa V, et al. Harmonic scalpel versus conventional electrosurgery in the treatment of vulvar cancer. Int J Gynaecol Obstet. 2008;103(2):185-8.

12. Achouri A, Huchon C, Bats AS, Bensaid C, Nos C, Lecuru F. Complications of lymphadenectomy for gynecologic cancer. Eur J Surg Oncol. 2013;39(1):81-6.

13. Tsimoyiannis EC, Jabarin M, Tsimoyiannis JC, Betzios JP, Tsilikatis C, Glantzounis G. Ultrasonically activated shears in extended lymphadenectomy for gastric cancer. World J Surg. 2002;26(2):158-61.

14. Friedman JF, Sunkara B, Jehnsen JS, Durham A, Johnson T, Cohen MS. Risk factors associated with lymphedema after lymph node dissection in melanoma patients. Am J Surg. 2015;210(6):1178-84.

15. Keskin O, Aksoy S, Babacan T, Sarici F, Kertmen N, Solak M, et al. Impact of the obesity on lymph node status in operable breast cancer patients. J BUON. 2013:18(4):824-30.

16. Mundhenk J, Hennenlotter J, Alloussi S, Selbherr D, Martzog JC, Todenhofer T, et al. Influence of body mass index, surgical approach and lymphadenectomy on the development of symptomatic lymphoceles after radical prostatectomy. Urol Int. 2013;90(3):270-6.

17. Andeweg CS, Schriek MJ, Heisterkamp J, Roukema JA. Seroma formation in two cohorts after axillary lymph node dissection in breast cancer surgery: does timing of drain removal matter? Breast J. 2011;17(4):359-64. 
18. Droeser RA, Frey DM, Oertli D, Kopelman D, Baas-Vrancken Peeters MJ, Giuliano AE, et al. Volume-controlled vs no/short-term drainage after axillary lymph node dissection in breast cancer surgery: a meta-analysis. Breast. 2009:18(2):109-14.

19. Matthey-Gie ML, Gie O, Deretti S, Demartines N, Matter M. Prospective Randomized Study to Compare Lymphocele and Lymphorrhea Control Following Inguinal and Axillary Therapeutic Lymph Node Dissection With or Without the Use of an Ultrasonic Scalpel. Ann Surg Oncol. 2016;23(5):1716-20.

20. Nessim C, Law C, McConnell Y, Shachar S, McKinnon G, Wright F. How often do level III nodes bear melanoma metastases and does it affect patient outcomes? Ann Surg Oncol. 2013;20(6):2056-64.

21. Guggenheim MM, Hug U, Jung FJ, Rousson V, Aust MC, Calcagni M, et al. Morbidity and recurrence after completion lymph node dissection following sentinel lymph node biopsy in cutaneous malignant melanoma. Ann Surg. 2008:247(4):687-93.

22. Kuroi K, Shimozuma K, Taguchi T, Imai H, Yamashiro H, Ohsumi S, et al. Evidence-based risk factors for seroma formation in breast surgery. Jpn J Clin Oncol. 2006;36(4):197-206.

23. He Q, Zhuang D, Zheng L, Fan Z, Zhou P, Zhu J, et al. Harmonic focus versus electrocautery in axillary lymph node dissection for breast cancer: a randomized clinical study. Clin Breast Cancer. 2012;12(6):454-8.

24. Sanguinetti A, Docimo G, Ragusa M, Calzolari F, D'Ajello F, Ruggiero R, et al. Ultrasound scissors versus electrocautery in axillary dissection: our experience. G Chir. 2010:31(4):151-3.

25. Currie A, Chong K, Davies GL, Cummins RS. Ultrasonic dissection versus electrocautery in mastectomy for breast cancer - a meta-analysis. Eur J Surg Oncol. 2012;38(10):897-901.

26. Yilmaz KB, Dogan L, Nalbant H, Akinci M, Karaman N, Ozaslan C, et al. Comparing scalpel, electrocautery and ultrasonic dissector effects: the impact on wound complications and pro-inflammatory cytokine levels in wound fluid from mastectomy patients. J Breast Cancer. 2011;14(1):58-63.

27. Kozomara D, Galic G, Brekalo Z, Sutalo N, Kvesic A, Soljic M. A randomised two-way comparison of mastectomy performed using harmonic scalpel or monopolar diathermy. Coll Antropol. 2010;34 Suppl 1:105-12.

28. Deo SV, Shukla NK, Asthana S, Niranjan B, Srinivas G. A comparative study of modified radical mastectomy using harmonic scalpel and electrocautery. Singapore Med J. 2002:43(5):226-8.

29. Kontos M, Kothari A, Hamed H. Effect of harmonic scalpel on seroma formation following surgery for breast cancer: a prospective randomized study. J BUON. 2008;13(2):223-30.

30. Galatius H, Okholm M, Hoffmann J. Mastectomy using ultrasonic dissection: effect on seroma formation. Breast. 2003;12(5):338-41.

\section{Submit your next manuscript to BioMed Central and we will help you at every step:}

- We accept pre-submission inquiries

- Our selector tool helps you to find the most relevant journal

- We provide round the clock customer support

- Convenient online submission

- Thorough peer review

- Inclusion in PubMed and all major indexing services

- Maximum visibility for your research

Submit your manuscript at www.biomedcentral.com/submit

) Biomed Central 